\title{
ANALISIS STRUKTUR NANO DARI LAPISAN TIPISCOBALT FERRITE YANG DIPREPARASI DENGAN METODE SPUTTERING
}

\author{
Ramli $^{1 *}$, Riri Jonuarti ${ }^{1}$, Ambran Hartono ${ }^{2}$ \\ ${ }^{1}$ Jurusan Fisika, FMIPA Universitas Negeri Padang \\ Jl. Prof. Hamka, Kampus UNP Air Tawar Padang 25131, INDONESIA \\ ${ }^{2}$ Program Studi Fisika, FST Universitas Islam Negeri Syarif Hidayatullah \\ J1. Juanda 95 Ciputat Tangerang Selatan, 17115, INDONESIA \\ ramli@fmipa.unp.ac.id, riri.jonuarti@gmail.com, ambranhartono@yahoo.com
}

\begin{abstract}
In this paper we report the results of studies relating to the synthesis of Cobalt Ferrite $\left(\mathrm{CoFe}_{2} \mathrm{O}_{4}\right)$ thin films by a sputtering method. The $\mathrm{CoFe}_{2} \mathrm{O}_{4}$ thin film has been prepared onto silicon substrate from the sputtering targets, CoFe. Structural propertiesofthinfilms were characterized byx-ray diffraction and the morphology was characterized by scanning electron microscopy. The growth parameter are: base pressure 2,8 $\times 10^{-2}$ Torr, ratio of Argon:Oxygen flow rate are 100:50 sccm, deposition pressure $5.4 \times 10^{-1}$ Torr, growth temperature $100^{\circ}$ C.Nanostructures of the thin film that have been analyzed are crystallite size and micro strain. We obtained the crystallite size of $\mathrm{CoFe}_{2} \mathrm{O}_{4}$ thin films for layer thickness of 40 and $48 \mathrm{~nm}$, respectively are: $32 \mathrm{~nm}$ and $66 \mathrm{~nm}$, while the micro strain is $8.0 \times 10^{-4}$ and $10.2 \times 10^{-4}$.
\end{abstract}

Keywords: $\mathrm{CoFe}_{2} \mathrm{O}_{4}$, grain size, micro strain,nanostructure, sputtering

\section{PENDAHULUAN}

Ahir-akhir ini, penelitian tentang oksida magnetik mengalami kemajuan yang sangat pesat. Strutur nano dari oksida magnetik merupakan salah satu nanomaterial yang penting dalam pengembangan beberapa material cerdas dan fungsional baru. Misalnya, Ferrite merupakan salah satu kandidat oksida magnetik yang potensial digunakan sebagai penyusun lapisan tipis giant magnetoresistance (Tezuka, 2012; Moussy, 2013). Ferrite termasuk oksida ferimagnetik dengan suhu Curie di atas suhu ruang. Seperti halnya material feromagnetik, di bawah suhu Curie material ferimagetik menunjukkan perilaku yang sama yakni menunjukan magnetisasi spontan pada suhu ruang karena memiliki momen magnetik total tidak nol, terdiri dari domain-domain magnetik jenuh dan memperlihatkan fenomena histeresis (Culity dan Graham, 2009).

Salah satu famili ferrite adalah cobalt ferrite $\left(\mathrm{CoFe}_{2} \mathrm{O}_{4}\right)$ yang memiliki suhu Curie $520^{\circ} \mathrm{C}$ (Cullity dan Graham, 2009). $\mathrm{CoFe}_{2} \mathrm{O}_{4}$ memiliki beberapa kelebihan yakni suhu Curie dan magnetisasi saturasi yang relatif tinggi, memiliki stabilitas kimia yang baik (Lee dkk, 1998), dan mudah 
dipreparasi serta harganya yang relatif murah.

Disamping itu, nanopartikel $\mathrm{CoFe}_{2} \mathrm{O}_{4}$ merupakan salah satu partikel yang sangat berpotensi diaplikasikan dalam bidang biomedis, diantaranya sebagai bahan pembawa target dalam pengiriman obat, cairan magnetik, dan sebagai katalis (Setiadi, 2013). Sementara itu,lapisan tipis $\mathrm{CoFe}_{2} \mathrm{O}_{4}$ telah dijadikan sebagai penyusun material penyusun sensor giant magnetoresistance (Djamal, 2015; Ramli, 2016), dandivais gelombang mikro (Hannour, 2014). Lapisan tipis $\mathrm{CoFe}_{2} \mathrm{O}_{4}$ merupakan komponen penting dalam multilayers atau komposit untuk penelitian multiferroic dan aplikasinya (Etier, 2015).

$\mathrm{CoFe}_{2} \mathrm{O}_{4}$ memiliki struktur spinel kubus (A) $\left[\mathrm{B}_{2}\right] \mathrm{O}_{4}$, dengan $\mathrm{A}$ dan $\mathrm{B}$ menyatakan tempat (site) koordinasi tetrahedral dan oktahedral seperti dalam Gambar 1. Dalam struktur ideal, ion-ion $\mathrm{Fe}^{3+}$ didistribusikan secara sama di site A dan $\mathrm{B}$, sementara ion-ion $\mathrm{Co}^{2+}$ dibatasi pada site $\mathrm{B}$, jadi strukturnya adalah: $\left(\mathrm{Fe}^{3+}\right)\left[\mathrm{Co}^{2+} \mathrm{Fe}^{3+}\right] \mathrm{O}_{4}$ seperti Gambar 2 .

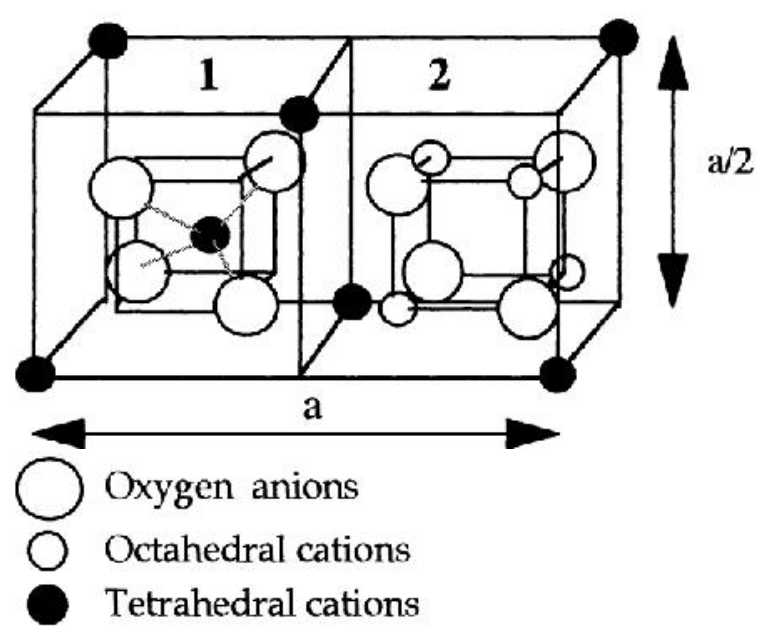

Gambar 1. Struktur spinel kubus ferrite (Dionne, 2009).

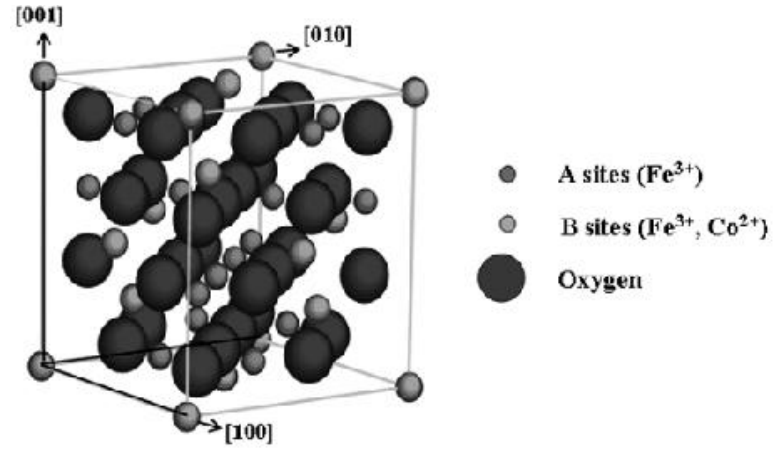

Gambar 2. Struktur kristal $\mathrm{CoFe}_{2} \mathrm{O}_{4}$ (Moussy, 2013)

\section{METODE PENELITIAN}

Jenis penelitian yang digunakan adalah penelitian eksperimental dengan diagramalir penelitian diperlihatkan dalam Gambar 3.

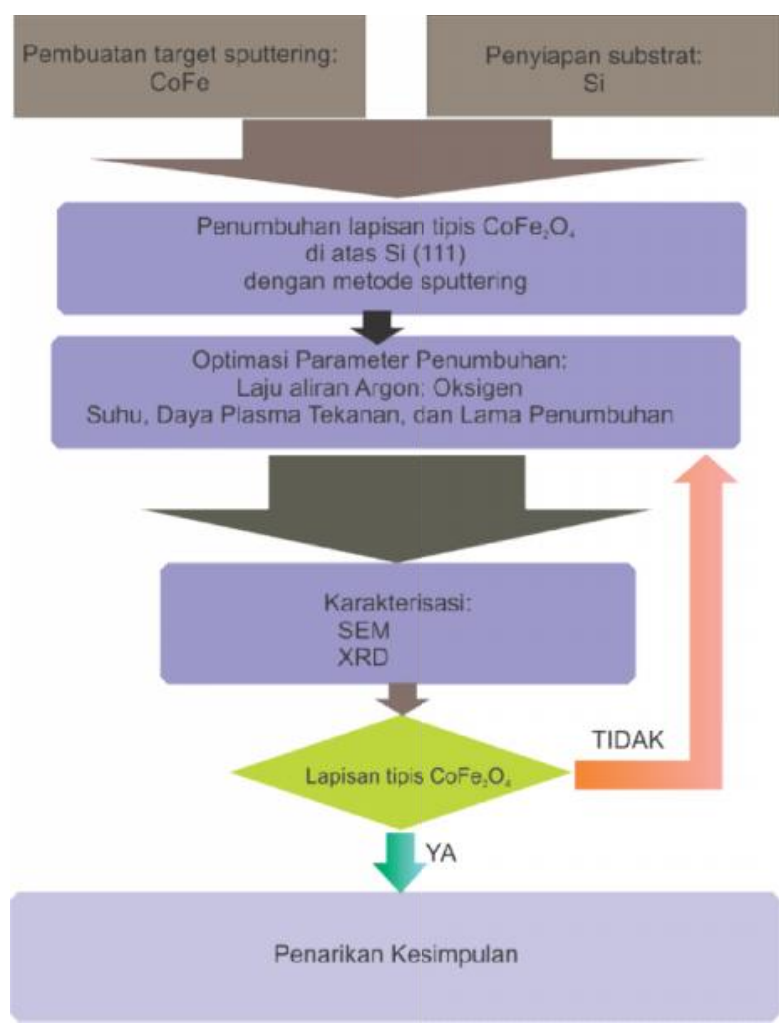

Gambar 3. Diagram alir penelitian

Penumbuhan lapisan tipis $\mathrm{CoFe}_{2} \mathrm{O}_{4}$ telah dilakukan dengan metode dcsputtering. Target sputtering dibuat dari paduan CoFe. Target sputtering dibuat 
dengan proses reaksi padatan. Bahan dasar target paduan $\mathrm{CoFe}$ terdiri dari bubuk logam Cobalt $(\mathrm{Co}=99.99 \%)$ dan bubuk logam Besi $(\mathrm{Fe}=99.99 \%)$ dengan komposisi molar 50:50 persen. Agar terbentuk lapisan tipis $\mathrm{CoFe}_{2} \mathrm{O}_{4}$ dari target $\mathrm{CoFe}$, maka selama proses sputtering dialiri dengan gas oksigen UHV. Sementara sebagai gas inner sputtering digunakan gas Argon UHV. Substrat yang digunakan silikon wafer dengan bidang (111).

Dalam eksperimen ini digunakan parameter penumbuhan: base pressure 2,8 x $10^{-2}$ Torr, lama penumbuhan divariasikan, laju aliran gas Argon:Oksigen $=100: 50$ sccm,tekanan deposisi $5.4 \times 10^{-1}$ Torr, tegangan plasma 600 volt dan temperatur penumbuhan $100^{\circ} \mathrm{C}$. Gas Argon yang digunakan memiliki kemurnian 99,999\%. Lama penumbuhan akan menentukan ketebalan lapisan tipis yang dihasilkan. Semakin lama waktu penumbuhan, semakin banyak atom-atom substrat yang ter-sputter yang akan menempel pada substrat, sehingga semakin tebal lapisan tipis yang dihasilkan. Dalam penelitian ini, ketebalan lapisan divariasaikandengan memvariasikan lama penumbuhannya.

Struktur nano lapisan tipis $\mathrm{CoFe}_{2} \mathrm{O}_{4}$ digunakan X-Ray Diffraction (XRD). Hasil pengukuran difraksi sinar $\mathrm{X}$ berupa difraktogram, dimana berdasarkan difraktogram tersebut dapat diketahui struktur dan kualitas kristal. Berdasarkan difraktogram dapat diungkapkan pula ukuran butir kristal dan strain mikro lapisan tipis $\mathrm{CoFe}_{2} \mathrm{O}_{4}$. Struktur kristal $\mathrm{CoFe}_{2} \mathrm{O}_{4}$ diperoleh dengan menganalisa difraktogram, menggunakan hubungan difraksi Bragg:

$$
n \lambda=2 d_{h k l} \sin (\theta),
$$

Dalam paper ini akan di analisis struktur nano dari lapisan tipis $\mathrm{CoFe}_{2} \mathrm{O}_{4}$ yangdiungkapkan dengan:
- Ukuran butir kristal dicari dengan formula Scherer (Suryanarayana dan Norton, 1998):

$$
D=\frac{k \lambda}{\beta \cos \theta}
$$

- Strain mikro (Suryanarayana dan Norton, 1998; Cetinkaya dkk, 2013):

$$
\varepsilon=\frac{\beta}{4 \tan \theta}
$$

dengan:

$D \quad$ : Ukuran butir

$\varepsilon \quad: \quad$ Strain mikro

$k \quad$ : $\quad$ Konstanta $(\sim 0,9)$

$\lambda \quad$ : Panjang gelombang sinar-X

$\beta \quad:$ FWHM

$\Theta \quad$ : $\quad$ Sudut difraksi Bragg

$d_{h k l} \quad$ : Jarak antar bidang kristal

Morfologipermukaan lapisan tipis $\mathrm{CoFe}_{2} \mathrm{O}_{4}$ diselidiki dengan Scanning Electron Microscopy (SEM). Selain digunakan untuk karakterisasi morfologi permukaan, hasil SEM juga digunakan untuk menghitung ketebalan lapisan yang terbentuk.

\section{HASIL DAN PEMBAHASAN}

Lapisan tipis $\mathrm{CoFe}_{2} \mathrm{O}_{4}$ telah ditumbuhkan di atas substrat $\mathrm{Si}$ (111). Untuk mengetahui bahwa lapisan tipis $\mathrm{CoFe}_{2} \mathrm{O}_{4}$ sudah tumbuh pada substrat, dilakukan karakterisasi SEM guna mempelajari morfologinya dan karakterisasi dengan XRD untuk melihat struktur kristal yang terbentuk.

Morfologi permukaan dari lapisan tipis $\mathrm{CoFe}_{2} \mathrm{O}_{4}$ yang ditumbuhkan di atas substrat $\mathrm{Si}$ (111) diperlihatkan dalam Gambar 2.Morfologi permukaan lapisan tipis $\mathrm{CoFe}_{2} \mathrm{O}_{4} / \mathrm{Si}$ terlihat halus dan homogen, meskipun demikian pertumbuhan butir sudah mulai tampak, permukaan 
lapisan tipis semakin homogen seperti terlihat dalam Gambar 3.

Waktu penumbuhan berpengaruh terhadap ketebalan lapisan tipis $\mathrm{CoFe}_{2} \mathrm{O}_{4} / \mathrm{Si}$, seperti terlihat pada citra SEM penampang lapisan tipis dalam Gambar 4.Terlihat dalam Gambar 4makin lama waktu penumbuhan, makin tebal lapisan yang terbentuk. Hal ini disebabkan dengan bertambahnya waktu penumbuhan, makin banyak fluks atom-atom yang menempel di permukaan substrat untuk membentuk lapisan tipis.

Hasil SEM penampang dalam Gambar 4 ini membuktikan bahwa lapisan tipis $\mathrm{CoFe}_{2} \mathrm{O}_{4} / \mathrm{Si}$ telah berhasil ditumbuhkan di atas substrat $\mathrm{Si}$ dengan metode sputtering. Disamping itu, Gambar 4 digunakan untuk menghitung tebal lapisan $\mathrm{CoFe}_{2} \mathrm{O}_{4}$ yang terbentuk. Hubungan antara perkiraan tebal lapisan $\mathrm{CoFe}_{2} \mathrm{O}_{4}$ yang terbentuk dengan lama penumbuhannya diperlihatkan dalam Gambar 5.
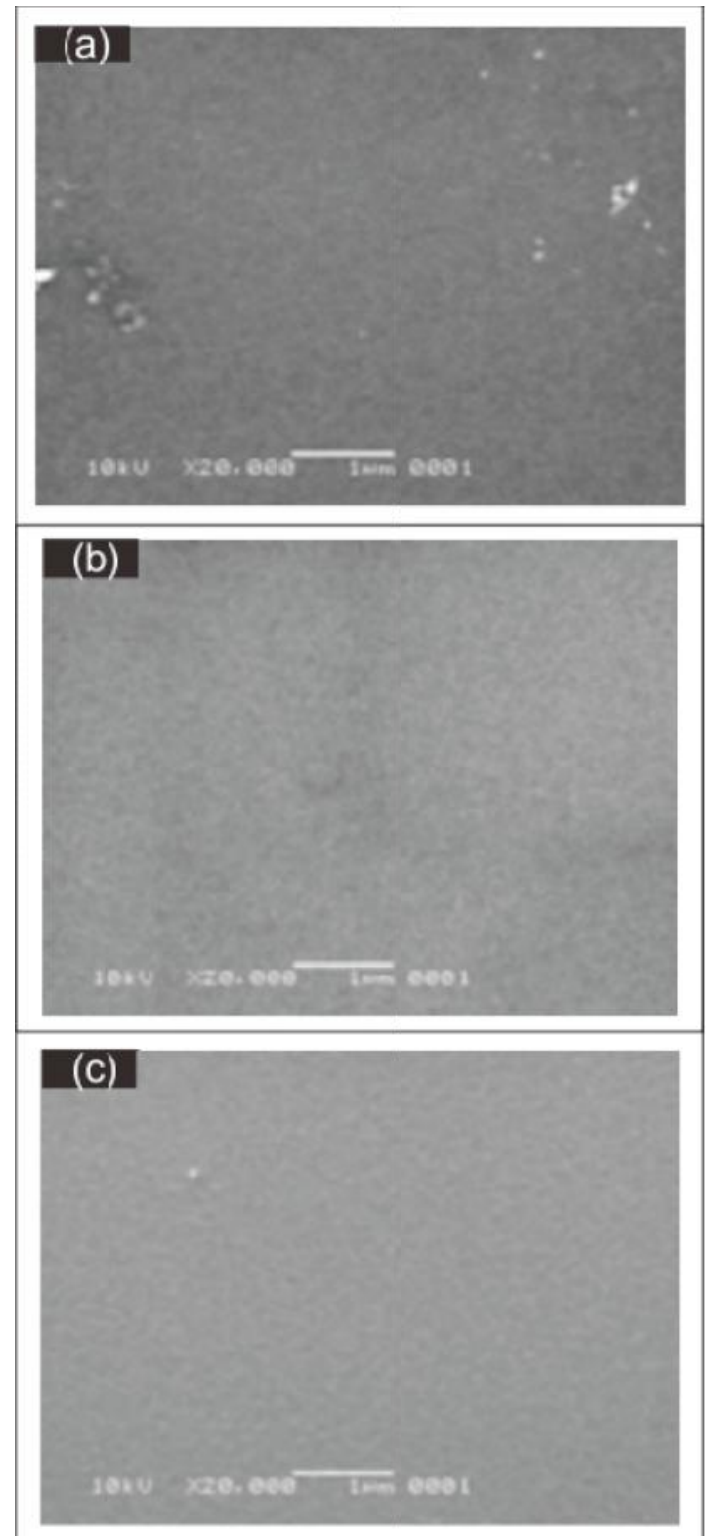

Gambar 2. Citra SEM permukaan lapisan tipis $\mathrm{CoFe}_{2} \mathrm{O}_{4} / \mathrm{Si}$ untuk lama penumbuhan yang berbeda (a) 3 menit, (b) 5 menit, dan (c) 10 menit. Perbesaran SEM adalah 20.000 kali.

Kemungkinan laju rata-rata penumbuhan lapisan tipis $\mathrm{CoFe}_{2} \mathrm{O}_{4} / \mathrm{Si}$ adalah $8,3 \mathrm{~nm} /$ menit. Pada penumbuhan lapisan tipis $\mathrm{CoFe}_{2} \mathrm{O}_{4} / \mathrm{Si}$, karena laju penumbuhan yang agak cepat maka adatom-adatom penyusun kristal $\mathrm{CoFe}_{2} \mathrm{O}_{4}$ lebih cepat bertumpuk dan memadat, sehingga kristal yang terbentuk kualitasnya lebih rendah. Hal ini didukung oleh hasil spektrum XRD untuk puncak $\mathrm{CoFe}_{2} \mathrm{O}_{4}$ 


\section{EKSAKTA Vol. 18 No.1 April 2017}

E-ISSN : 2549-7464, P-ISSN : 1411-3724

yang terlihat rendah dan mempunyai pelebaran yang lebih besar (Gambar 6).
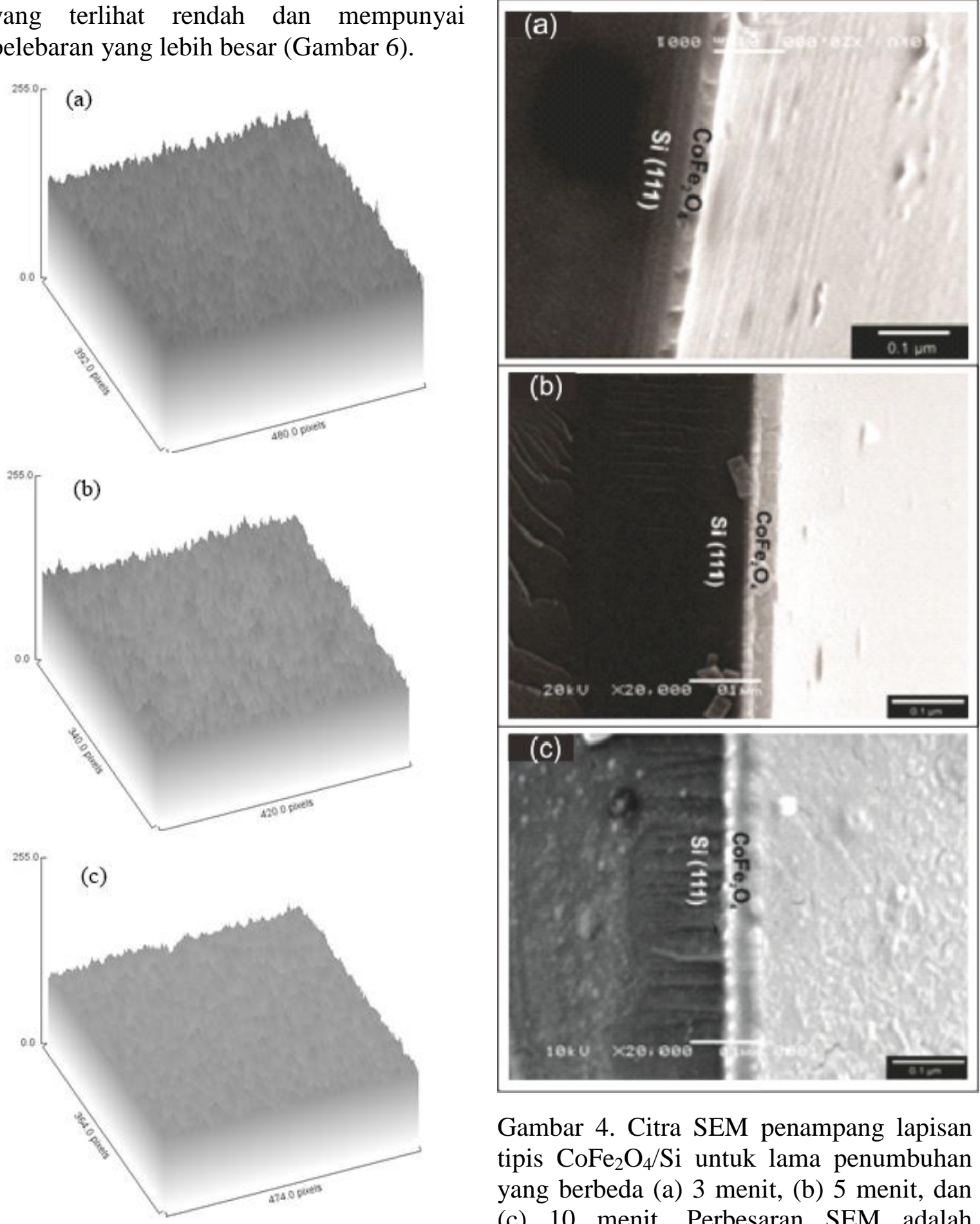

Gambar 4. Citra SEM penampang lapisan tipis $\mathrm{CoFe}_{2} \mathrm{O}_{4} / \mathrm{Si}$ untuk lama penumbuhan yang berbeda (a) 3 menit, (b) 5 menit, dan (c) 10 menit. Perbesaran SEM adalah

Gambar 3. Pertumbuhan butir lapisan tipis $\mathrm{CoFe}_{2} \mathrm{O}_{4}$ untuk lama penumbuhan: (a). 3 menit, (b). 5 menit, dan (c). 10 menit. 20.000 kali.

Hasil pengukuran XRD untuk lapisan tipis $\mathrm{CoFe}_{2} \mathrm{O}_{4} / \mathrm{Si}$ seperti diperlihatkan dalam Gambar 5, tampak bahwa fasa kristal yang muncul untuk ketebalan $27 \mathrm{~nm}$ adalah CoFe (200) pada sudut $2 \theta=65,0^{\circ}$, sedangkan untuk ketebalan $40 \mathrm{~nm}$ dan 48 
nm orientasi kristal yang muncul adalah $\mathrm{CoFe}_{2} \mathrm{O}_{4}(620)$ pada sudut $2 \theta=70,9^{0}$. Hal ini menunjukkan telah terjadi transformasi fasa selama lapisan tipis tumbuh dari ketebalan $27 \mathrm{~nm}$ ke $40 \mathrm{~nm}$. Munculnya puncak $\mathrm{CoFe}$ yang merupakan target sputtering, diperkirakan belum sempurnanya penyatuan oksigen dalam lapisan, karena waktu penumbuhan yang masih kurang. Namun ketika lama penumbuhan di tambah, maka puncak $\mathrm{CoFe}$ bertransformasi menjadi $\mathrm{CoFe}_{2} \mathrm{O}_{4}$.
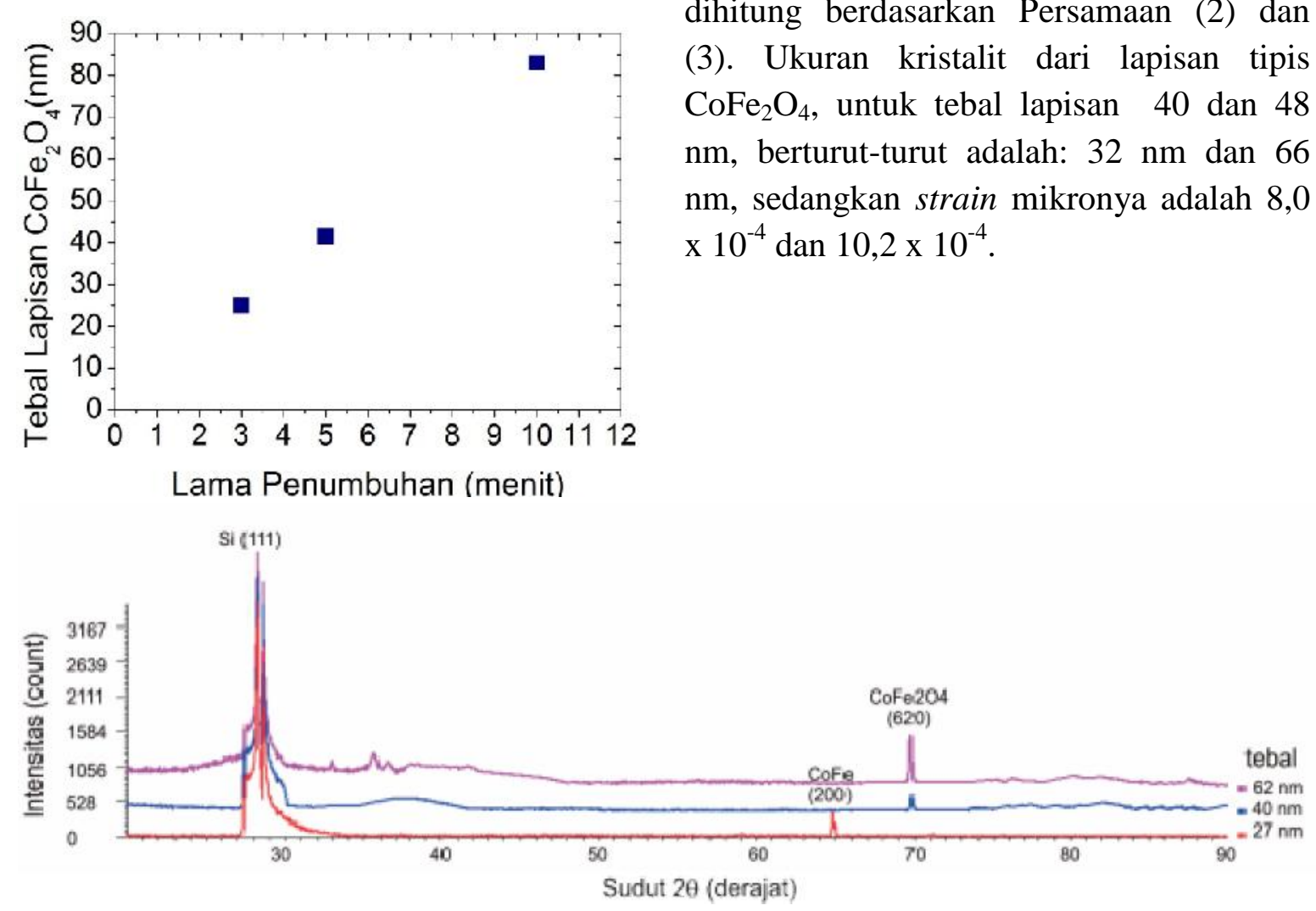

Gambar 6. Pola difraksi dari lapisan tipis $\mathrm{CoFe}_{2} \mathrm{O}_{4} / \mathrm{Si}$ untuk ketebalan $27 \mathrm{~nm}$, 40nm dan $48 \mathrm{~nm}$. Sinar $\mathrm{X}$ yang digunakan memiliki $\lambda=1,54056 \AA$
Gambar 5. Hubungan tebal lapisan $\mathrm{CoFe}_{2} \mathrm{O}_{4} / \mathrm{Si}$ dengan lama penumbuhannya

Pelebaran puncak kristal yang muncul berdasarkan hasil XRD diperlihatkan dalam Gambar 7. Pelebaran ini menentukan kualitas kristal lapisan tipis $\mathrm{CoFe}_{2} \mathrm{O}_{4}$ yang telah ditumbuhkan.

Kualitas kristal diidentifikasi dari ukuran kristalit dan strain mikro yang dihitung berdasarkan Persamaan (2) dan (3). Ukuran kristalit dari lapisan tipis $\mathrm{CoFe}_{2} \mathrm{O}_{4}$, untuk tebal lapisan 40 dan 48 $\mathrm{nm}$, berturut-turut adalah: $32 \mathrm{~nm}$ dan 66 $\mathrm{nm}$, sedangkan strain mikronya adalah 8,0 x $10^{-4}$ dan $10,2 \times 10^{-4}$. 


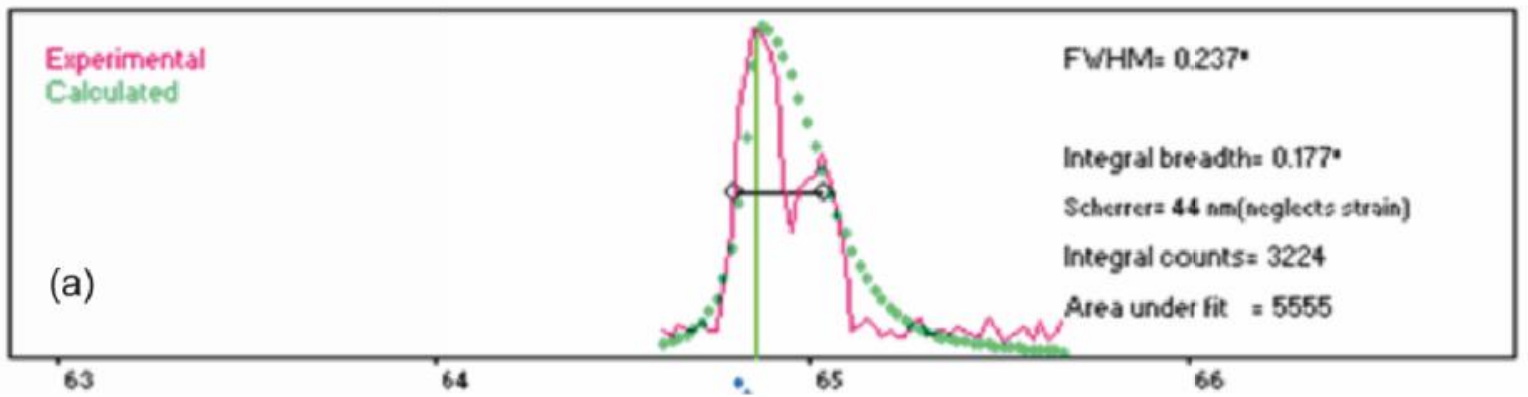

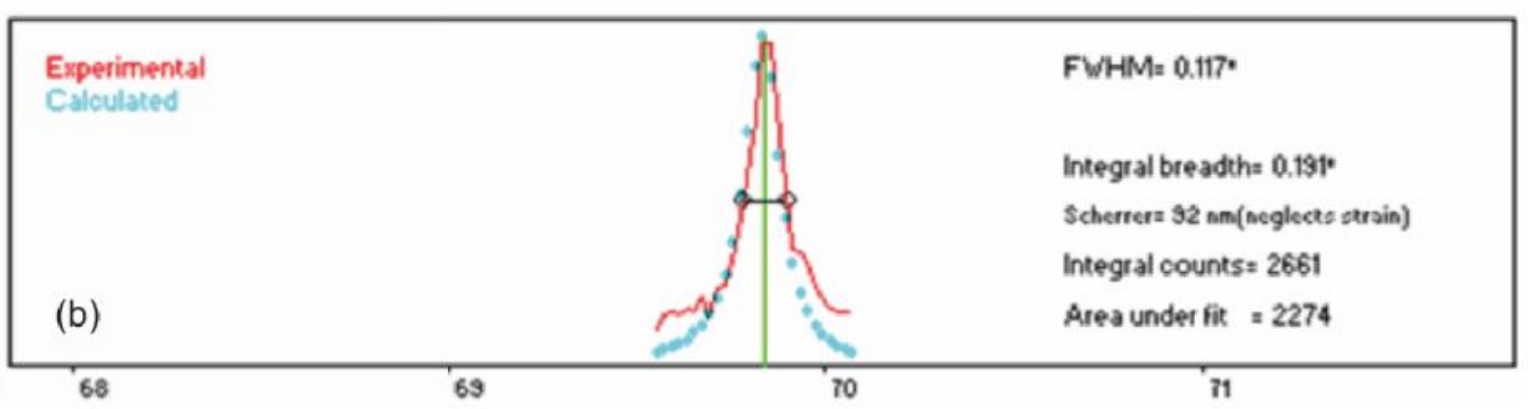

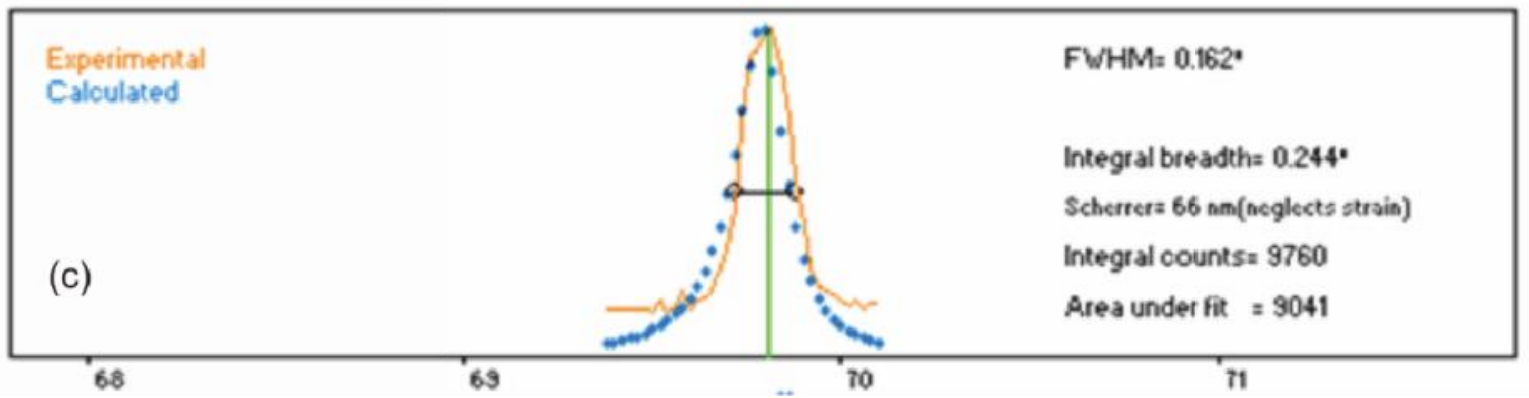

Gambar 7. FWHM dari lapisan tipis $\mathrm{CoFe}_{2} \mathrm{O}_{4} / \mathrm{Si}$ untuk ketebalan (a) $27 \mathrm{~nm}$, (b) $40 \mathrm{~nm}$ dan (c) $48 \mathrm{~nm}$.

\section{KESIMPULAN}

Telah berhasil ditumbuhkan lapisan tipis $\mathrm{CoFe}_{2} \mathrm{O}_{4} / \mathrm{Si}$ dengan orientasi kristal (620) pada sudut $2 \theta=70,9^{0}$. Penumbuhan lapisan tipis $\mathrm{CoFe}_{2} \mathrm{O}_{4} / \mathrm{Si}$ menunjukkan telah terjadi transformasi fasa selama lapisan tipis tumbuh dari ketebalan $27 \mathrm{~nm}$ ke 40 nm. Ketika ketebalan lapisan tipis $\mathrm{CoFe}_{2} \mathrm{O}_{4}$ bertambah dari $40 \mathrm{ke} 48 \mathrm{~nm}$, maka ukuran kristalit dan strain mikro bertambah.

\section{UCAPAN TERIMAKASIH}

Penulis mengucapkan terimakasih kepada Direktorat Riset dan Pengabdian Masyarakat, Menristekdikti, yang telah memberi bantuan dana penelitian melalui skema Penelitian Dosen Pemula (PDP) tahun 2016.

\section{DAFTAR PUSTAKA}

Cetinkaya. S., Cetinkara. H.A., Bayansal. F., Kahraman. S., (2013): Growth and Characterization of $\mathrm{CuO}$ Nanostructures on $\mathrm{Si}$ for the Fabrication of $\mathrm{CuO} / \mathrm{p}-\mathrm{Si}$ Schottky Diodes, The Scientific World Journal, 13, 126982.

Culity. B.D., \& Graham. C.D., (2009)., Introduction to Magnetic 
Materials, John Wiley \& Sons, Inc, 183-189.

Dionne, G.F., (2009): Magnetic Oxides, Springer, New York

Djamal, M., Ramli., Khairurrijal., Haryanto, F., (2015), Development of Giant Magnetoresistance Material Based on Cobalt Ferrite, Acta Physica Polonica A, Vol. 128 No. 2B, pp. 19-22.

Ramli, Hartono, A., Sanjaya, E.,Aminudin, A., Khairurrijal,. Haryanto, F., Imawan, C.,\& Djamal, M., (2016), Novel

Ternary $\mathrm{CoFe}_{2} \mathrm{O}_{4} / \mathrm{CuO} / \mathrm{CoFe}_{2} \mathrm{O}_{4}$ as a Giant Magnetoresistance Sensor, J. Math. Fund. Sci., Vol. 48, No. 3, 2016, pp. 230-24

Etier, M., Schmitz-Antoniak, C., Salamon, S., Trivedi, H., Gao, Y., Nazrabi, A., Landers, J., Gautam, D., Winterer, M., Schmitz, D., Wende, H., Shvartsmana, V.V., Lupascua, D.C., (2015)., Magnetoelectric coupling on multiferroic cobalt ferritebarium titanate ceramic composites with different connectivity schemes, Acta Materialia, Vol. 90, pp. 1-9.

Hannour, A., Vincent, D., Kahlouche, F., Tchangoulian, A., Neveu, S., Dupuis, V., (2014), Self-biased cobalt ferrite nanocomposites for microwave applications, Journal of Magnetism and Magnetic Materials, Vol. 353, pp. 29-33.

Lee. J., Park. J.Y., Oh. Y., \& Kim. C.S., (1998)., Magnetic Properties of CoFe2O4 Tin Films Prepared by a sol-gel Method, J. Appl. Phys. 84(5), 2801-2804.
Moussy, J.P., (2013): From epitaxial growth of ferrite thin films to spinpolarized tunnelling, J. Phys. D: Appl. Phys. 46143001.

Setiadi, E. A, Nanda. S, Hesti. R, N. Fadhilah, Takhesi. K, Sathosi. W, dan Edi. S, (2013): Sintesis Nanopartikel Cobalt Ferrite $\left(\mathrm{CoFe}_{2} \mathrm{O}_{4}\right)$ dengan Metode Kopresipitasi dan Karakterisasi Sifat Kemagnetannya, Indonesian Journal of Applied Physics, Vol.3 No.1, 55.

Suryanarayana. C., Norton. M., (1998): XRay Diffraction: A Practical Approach, Plenum Press, New York. Tezuka, N., (2012),,New Materials Research for High Spin Polarized Current, J. Mag. Magn. Matter. 324, 3588-3592, 